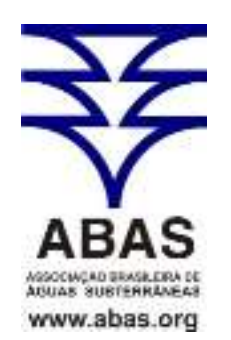

\title{
RELAÇÃO ENTRE PADRÕES HIDROQUÍMICOS E AS PROFUNDIDADES DE FRATURAS COM ENTRADAS DE ÁGUA EM ROCHAS VULCÂNICAS ÁCIDAS DA FORMAÇÃO SERRA GERAL
}

\author{
RELATIONSHIP BETWEEN HYDROCHEMICAL PATTERNS AND DEPTHS \\ OF WATER BEARING FRACTURES IN ACID VOLCANIC ROCKS FROM \\ SERRA GERAL FORMATION
}

\author{
Taison Anderson Bortolin ${ }^{1}$; Pedro Antonio Roehe Reginato ${ }^{2}$; Marcos Imério Leão ${ }^{3}$; \\ Vania Elisabete Schneider ${ }^{4}$
}

Artigo recebido em: 11/02/2016 e aceito para publicação em: 18/04/2016.

DOI: http://dx.doi.org/10.14295/ras.v30i1.28585

\begin{abstract}
Resumo: Este trabalho buscou avaliar a existência de diferentes padrões hidroquímicos dos aquíferos fraturados do Sistema Aquífero Serra Geral (SASG), relacionando esses padrões com as profundidades das entradas de água, no município de Carlos Barbosa-RS. Para este trabalho foram utilizadas informações hidroquímicas da água referentes a duas amostragens realizadas em 12 poços tubulares e 3 fontes. Para análise dos dados empregou-se os diagramas de Schoeller e Stiff, além da análise estatística de agrupamento, a fim de verificar padrões semelhantes entre os pontos amostrados. Observou-se uma boa correlação entre os padrões hidroquímicos e a profundidade das entradas de água, o que permitiu a elaboração de um modelo conceitual hidroquímico, onde foram identificadas águas com baixa concentração de íons em grupo de poços que possuem entradas de água localizadas em profundidades inferiores a 30 metros. Também foi identificado um grupo de poços cujas entradas de água estão localizadas entre 50 e 112 metros e apresentam águas com maior concentração de íons como cálcio, sódio, bicarbonatos. A explicação dessas diferenças pode estar relacionada com a circulação de água e com tempo de interação água-rocha que ocorre de forma diferente dependendo da profundidade das entradas de água.
\end{abstract}

Palavras-chave: Hidroquímica. Aquíferos fraturados. Sistema Aquífero Serra Geral.

\begin{abstract}
This study aimed to evaluate the existence of different hydrochemical patterns of fractured aquifers of the Serra Geral Aquifer System (SGAS), relating these patterns with the depths of the fractures bearing water in the city of Carlos Barbosa-RS. Hydrochemical information from samples collected in 12 wells and 3 springs along two sampling campaigns were used for this work. Schoeller and Stiff diagrams were employed for data analysis, beyond the statistical cluster analysis in order to verify similar patterns between the sampled points. Good correlation between hydrochemical patterns and the depth of the fractures bearing water were observed, allowing the identification of two groundwater groups. One group of wells aggregates samples presenting low concentration of ions associated to fractures depths located less than 30 meters, the second group is constituted by wells presenting high concentration of ions such as calcium, sodium, bicarbonates, and fractures depths located between 50 and 112 meters. The explanation of these differences can be related to the movement of water and water-rock interaction occurs differently depending on the depth of water inflow.
\end{abstract}

Keywords: Hydrochemical. Fractured aquifers. Serra Geral Aquifer System.

\section{INTRODUÇÃO}

O Sistema Aquífero Serra Geral é um dos principais sistemas hidrogeológicos do Estado do Rio Grande do Sul, devido, princi- palmente, à utilização de suas águas para diversas atividades, tais como abastecimento público, agropecuária e indústria.

Nessa região, os recursos hídricos subterrâneos estão associados às rochas vul-

1-3 Instituto de Pesquisas Hidráulicas (IPH) - Universidade Federal do Rio Grande do Sul (UFRGS) (tabortol@ucs.br; pedro.reginato@ufrgs.br; imerio@iph.ufrgs.br)

4 Instituto de Saneamento Ambiental (ISAM) - Universidade de Caxias do Sul (UCS) (veschnei@ucs.br) 
cânicas da Formação Serra Geral, predominando dois tipos de aquíferos: o granular (freático) e o fraturado (REGINATO, 2003). $\mathrm{O}$ primeiro aquífero fornece volumes reduzidos de água, sendo mais utilizado pela população rural, que capta suas águas através de poços escavados ou fontes. O segundo aquífero fornece maiores volumes e água com melhor qualidade, sendo utilizado para abastecimento da população urbana da maioria dos municípios, bem como de algumas comunidades rurais, através de poços tubulares comunitários.

As águas que circulam por esses aquíferos apresentam características hidroquímicas e qualidade variada. Essa diferenciação depende do tipo de aquífero, da litologia, da recarga, do grau de confinamento, da vulnerabilidade, do uso e ocupação do solo na área de recarga e junto ao ponto de captação (REGINATO, 2003; REGINATO et al., 2012).

Além disso, a assinatura hidroquímica da água subterrânea é definida em função das características geológicas do aquífero, da solubilidade dos minerais constituintes da rocha aquífera, dos meios por onde a água percola antes de atingir a zona saturada e do tempo de armazenamento (MIZUNO, 2012). A interação água-rocha é incrementada em zonas fraturadas, onde o grau de alteração aumenta proporcionalmente com a densidade de fraturas, promovendo maior atividade nas reações de troca iônica (BETIOLO, 2006). Cada fratura pode apresentar particularidades específicas, ainda que esteja na mesma região hidrogeológica, podendo ocorrer diferenças químicas também em função da região de recarga.

Diante destas considerações, este trabalho busca avaliar a existência de diferentes padrões hidroquímicos dos aquíferos fraturados do Sistema Aquífero Serra Geral (SASG), relacionando esses padrões com a ocorrência de entradas de água localizadas em diferentes profundidades. Este estudo favorecerá um melhor entendimento das características deste sistema aquífero, facilitando a compreensão quanto aos padrões de circulação, recarga e alterações hidroquímicas.

\section{2 ÁREA DE ESTUDO}

A área de estudo está localizada na região nordeste do Estado do Rio Grande do Sul, mais precisamente na zona urbana do município de Carlos Barbosa (Figura 1), inserida na região do planalto. $\mathrm{O}$ município está localizado a $676 \mathrm{~m}$ acima do nível do mar, sendo a altitude da sede em 618 m. Encontra-se entre as coordenadas geográficas $29^{\circ} 18^{\prime}$ de Latitude Sul e $51^{\circ} 30^{\prime}$ de Longitude Oeste, abastecido em sua totalidade por águas subterrâneas.

A área de estudo é marcada pela ocorrência de rochas vulcânicas pertencentes à Formação Serra Geral, cuja formação geológica apresenta sequências de rochas vulcânicas básicas, intermediárias e ácidas que juntas atingem espessuras médias de 800 metros e máxima de 1500 metros (ROISEMBERG e VIERO, 2002).

Especificamente na região de estudo há ocorrência de dois tipos principais de litologias associadas a diferentes unidades que são: basaltos do tipo Gramado e vulcânicas ácidas do tipo Palmas/Caxias (CPRM, 2010).

Considerando a classificação do mapa hidrogeológico do Rio Grande do Sul (VIERO E SILVA, 2010), o local de estudo se concentra na área de ocorrência dos Aquíferos Fissurais Serra Geral, mais precisamente no Sistema Aquífero Serra Geral II. Nesta região, as áreas que contém águas subterrâneas estão representadas por aquíferos fraturados que são condicionados por estruturas tectônicas (fraturas e falhas) e de resfriamento das rochas vulcânicas (REGINATO et al. 2015). 

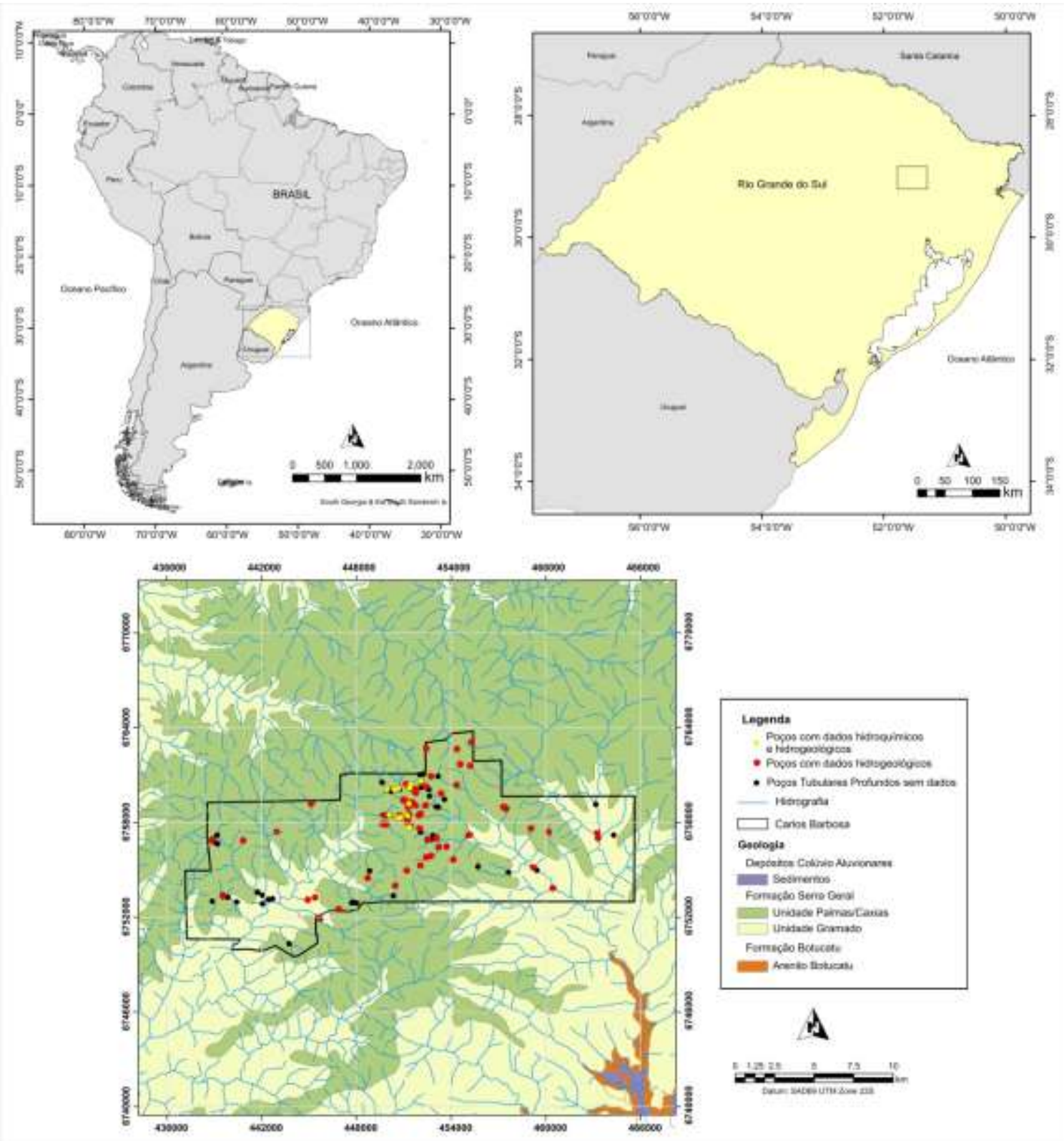

Figura 1 - Localização da área de estudo Figure 1 - Location of the study area

\section{MATERIAL E MÉTODOS}

Para o desenvolvimento desse estudo foram realizados o inventário e cadastramento de poços tubulares existentes na região, o levantamento e interpretação de dados geológicos e hidrogeológicos, além da coleta e análise de amostras de água de 12 poços tubulares e 3 fontes. Os dados obtidos com o desenvolvimento das atividades anteriormente descritas foram avaliados com o emprego de técnicas estatísticas e relacionados com as profundidades das entradas de água identificadas nos poços tubulares.
3.1 Cadastro de poços e interpretação hidrogeológica

O cadastro de poços tubulares foi realizado por meio de consulta ao Sistema de Informações de Águas Subterrâneas (SIAGAS-CPRM) e ao banco de dados pertencente a Companhia Riograndense de Abastecimento (CORSAN). Desse levantamento foram selecionados os poços que continham informações geológicas, hidrogeológicas e construtivas como, por exemplo: boletim de perfuração, perfil geológico e construtivo, nível estático, nível dinâmico, parâmetros 
hidrodinâmicos (transmissividade e capacidade especifica), vazão, entre outros dados. Essas informações foram organizadas e armazenadas num banco de dados criado com o uso do programa Visual Poços Pro (SCHLUMBERGER, 1998). Os poços que continham essas informações foram os poços da CORSAN.

Posteriormente foram realizadas campanhas de campo para cadastro dos poços tubulares de propriedade da CORSAN. Com base na informação de altitude e profundidade dos poços foram selecionadas áreas, nas quais realizou-se levantamentos geológicos de campo para identificação de litologias, estruturas tectônicas e estruturação dos derrames vulcânicos. Esses dados foram utilizados para avaliar a ocorrência de rochas vulcânicas ácidas e básicas bem como da quantidade e estruturação dos derrames, pois os poços, em função da profundidade interceptam diferentes derrames de rochas vulcânicas. Os dados obtidos com o levantamento geológico foram comparados com os dados apresentados nos perfis geológicos dos poços.

Com base na análise dos perfis geológicos dos poços, boletins de perfuração e dados obtidos com o levantamento geológico de campo, foram identificadas as entradas de água presentes nos poços, determinada a quantidade de entradas e a profundidade de ocorrência das mesmas. Além disso, foram identificadas as litologias que estavam associadas a cada entrada e sua relação com o derrame de rochas vulcânicas (nível do derrame ou contato entre derrames). Essas informações foram utilizadas para comparar os resultados das análises químicas e avaliar a ocorrência de padrões hidroquímicos associados a essas entradas.

\subsection{Caracterização hidroquímica}

A caracterização hidroquímica foi realizada com base na interpretação dos resultados de análises físico-químicas realizadas em amostras de água subterrânea coletadas de poços tubulares e fontes. A seleção dos poços foi realizada com base nas informações geológicas, hidrogeológicas e construtivas disponíveis para os poços cadastrados, sendo que os poços selecionados deveriam captar água de aquíferos associados às rochas vulcânicas ácidas.

Além disso, para seleção dos poços foi levada em consideração as informações sobre as entradas de água (quantidade e profundidade). Com relação à quantidade, foram selecionados poços que apresentavam uma entrada de água ou duas (quando ocorriam próximas e no mesmo nível do derrame). Já no caso de profundidade foram selecionados poços que apresentavam entradas de água em diferentes níveis, pois com isso seria possível avaliar a influência da profundidade no controle hidroquímico. Dessa forma, foram selecionados 12 poços tubulares pertencentes à CORSAN e 3 fontes de encosta, onde foram realizadas duas campanhas de amostragem de água subterrânea nos meses de abril e julho de 2013.

Para coleta, utilizou-se o sistema de bombeamento do poço, pois os poços são utilizados para captação de água para abastecimento da cidade. Dessa forma, a coleta foi realizada durante as etapas de bombeamento dos poços. Quando algum poço estava em repouso, a bomba foi ligada, sendo que a coleta foi realizada após, pelo menos $10 \mathrm{mi}$ nutos de bombeamento. Após esse tempo, realizou-se a coleta das amostras de água na saída da tubulação ligada à bomba.

Para cada ponto foram coletadas amostras e enviadas para análise laboratorial dos parâmetros ferro, bicarbonatos, manganês, fluoretos, alcalinidade total, cloreto, sulfato, cálcio, magnésio, sódio e potássio. Parâmetros como $\mathrm{pH}$, condutividade elétrica e temperatura foram medidos em campo, utilizando uma sonda multiparâmetros Horiba U50. A Tabela 1 apresenta a metodologia usada pelo laboratório para os parâmetros analisados. 
BORTOLIN, T. A.; REGINATO, P. A. R.; LEÃO, M. I.; SCHNEIDER, V. E.

Tabela 1 - Metodologias analíticas utilizadas na análise das amostras de água

Table 1 - Analytical methodologies used in the analysis of water samples

\begin{tabular}{ll}
\hline Ensaio & Metodologia Utilizada \\
\hline Alcalinidade total $(\mathrm{mg} / \mathrm{L})$ & SMEWW* - Método 2320B \\
Bicarbonatos $(\mathrm{mg} / \mathrm{L})$ & SMEWW - Método 2320B \\
Cloretos $(\mathrm{mg} / \mathrm{L})$ & SMEWW - Método 4500 Cl-B \\
Sulfatos $(\mathrm{mg} / \mathrm{L})$ & SMEWW - Método 4500 $\mathrm{SO}_{4}{ }^{-B}$ \\
Fluoretos $(\mathrm{mg} / \mathrm{L})$ & SMEWW - Método 4500 F B \\
Ferro total $(\mathrm{mg} / \mathrm{L})$ & SMEWW - Método 3030 E e 3111B \\
Manganês total $(\mathrm{mg} / \mathrm{L})$ & SMEWW - Método 3030 E e 3111B \\
Magnésio $(\mathrm{mg} / \mathrm{L})$ & SMEWW - Método 3030 E e 3111B \\
Cálcio $(\mathrm{mg} / \mathrm{L})$ & SMEWW - Método 3030 E e 3111B \\
Sódio $(\mathrm{mg} / \mathrm{L})$ & SMEWW - 3500 Na - B \\
Potássio $(\mathrm{mg} / \mathrm{L})$ & SMEWW - 3500 K - B \\
pH & Sonda Multiparâmetros Horiba U-50 \\
Condutividade Elétrica (uS/cm) & Sonda Multiparâmetros Horiba U-50 \\
Sólidos Dissolvidos Totais $(\mathrm{mg} / \mathrm{L})$ & Sonda Multiparâmetros Horiba U-50 \\
Temperatura $\left({ }^{\circ} \mathrm{C}\right)$ & Sonda Multiparâmetros Horiba U-50 \\
\hline *SMEWW: Standard Methods for Examination of Water and Wastewater (2012), 22 ${ }^{\mathrm{a}}$ edição
\end{tabular}

A avaliação dos relatórios analíticos foi feita com base na seleção dos parâmetros analisados e na elaboração de diagramas de Stiff (STIFF, 1951) e Schoeller (SCHOELLER, 1935) com o uso do software AcquaChem 5.1 (SCHLUMBERGER, 2008). Os parâmetros hidroquímicos foram comparados com as profundidades das entradas da água identificadas no poço, visando com isso avaliar a ocorrência de diferenças ou semelhanças no padrão hidroquímico dessas águas.

\subsection{Análise estatística}

Para a compreensão da hidroquímica de determinado grupo de amostras, foram analisados o comportamento e a distribuição de determinada variável dentro do conjunto de amostras através de análise estatística e testes não-paramétricos. Nesta pesquisa, utilizou-se o teste estatístico não paramétrico de Kruskal-Wallis, a um nível de significância de $5 \%$, a fim de avaliar diferenças entre os pontos coletados, a partir dos parâmetros hidroquímicos analisados. Tal teste foi aplicado pela amostra ser pequena e pelas suposições de normalidade de dados exigidas pela Análise de Variância não serem alcançadas.

Uma segunda análise estatística consistiu na análise de agrupamentos (cluster analisys) a qual utiliza a similaridade entre indivíduos para classificá-los hierarquica- mente em grupos, considerando o conjunto de variáveis utilizadas para cada indivíduo. Isso possibilitou definir poços com as mesmas características comparando-os com as diferentes profundidades de entradas d'água.

O processamento das informações foi efetuado utilizando-se o software SYSTAT, versão 12.0 (SYSTAT, 2007). Para se eliminar o efeito de escala e unidades, a padronização dos dados processados foi realizada com a conversão das variáveis para escores padrão ( $\mathrm{Z}$ escore). $\mathrm{O}$ algoritmo de agrupamento empregado foi o método Ward, utilizado por diversos autores na análise de dados hidroquímicos e hidrogeológicos (GÜLER et al. 2002; ALMEIDA, 2009; MONTEIRO et al., 2010; FERNANDES, 2010).

O método para definir a distância de similaridade no agrupamento dos indivíduos foi a distância Euclidiana, a qual considera que a distância entre dois casos $\left(d_{i j}\right)$ é a raiz quadrada do somatório dos quadrados das diferenças entre valores de $i$ e $j$ para todas as variáveis $(v=1,2, \ldots, p)$, conforme apresenta a Equação 1.

$$
d_{i j}=\sqrt{\sum_{v=1}^{p}\left(x_{i v}-x_{j v}\right)^{2}}
$$

onde: $X_{i v}$ representa a característica do indivíduo $\mathrm{i} ; X_{j v}$ representa a característica 
do indivíduo $\mathrm{j}$; $p$ é o número de parcelas na amostra; e $v$ é o número indivíduo na amostra.

O ponto de corte do dendrograma, para definir o número de grupos fundamentouse na técnica apresentada por Corrar et al. (2009) em que o corte ocorre no momento em que a distância reescalonada do coeficiente de aglomeração apresenta a maior variação.

\section{RESULTADOS E DISCUSSÕES 4.1 Caracterização Hidrogeológica}

A análise das rochas e estruturas observadas em cada um dos afloramentos observados em campo permitiu a identificação da ocorrência de sete tipos de derrames vulcânicos nos quais estão relacionadas as entradas de água, sendo dois básicos e cinco ácidos, conforme dados apresentados na Tabela 2 .

Tabela 2 - Tipos de Rochas e Derrames identificados na área e suas altitudes aproximadas Table 2 - Types of rocks and Stroke identified in the area and their approximate levels

\begin{tabular}{cll}
\hline $\begin{array}{c}\text { Altitude (Aproxima- } \\
\text { da) }\end{array}$ & \multicolumn{1}{c}{ Rocha } & \multicolumn{1}{c}{ Derrame } \\
\hline$>\mathbf{6 9 8}$ & Riodacito & Derrame Ácido 5 \\
$\mathbf{6 4 9}$ a 698 & Riolito / Dacito & Derrame Ácido 4 \\
$\mathbf{6 2 0}$ a 649 & Riodacito & Derrame Ácido 3 \\
$\mathbf{5 6 1}$ a 620 & Riodacito & Derrame Ácido 2 \\
$\mathbf{5 0 0}$ a 561 & Riolito & Derrame Ácido 1 \\
$\mathbf{4 4 5}$ a 500 & Basalto & Derrame Básico 2 \\
até 445 & Basalto & Derrame Básico 1 \\
\hline
\end{tabular}

Na Figura 2 é apresentada a localização dos 12 poços e 3 fontes que foram utilizados na caracterização hidroquímica da água subterrânea que ocorre associada às rochas vulcânicas ácidas do Município de Carlos Barbosa. Na mesma figura pode-se visualizar dois perfis geológicos que representam a área de estudo.
Na Tabela 3 são apresentados os dados dos poços e fontes bem como as informações sobre a profundidade das entradas de água e sua relação com os derrames de rochas ácidas identificados no levantamento de campo e nos perfis geológicos dos poços. 
BORTOLIN, T. A.; REGINATO, P. A. R.; LEÃO, M. I.; SCHNEIDER, V. E.
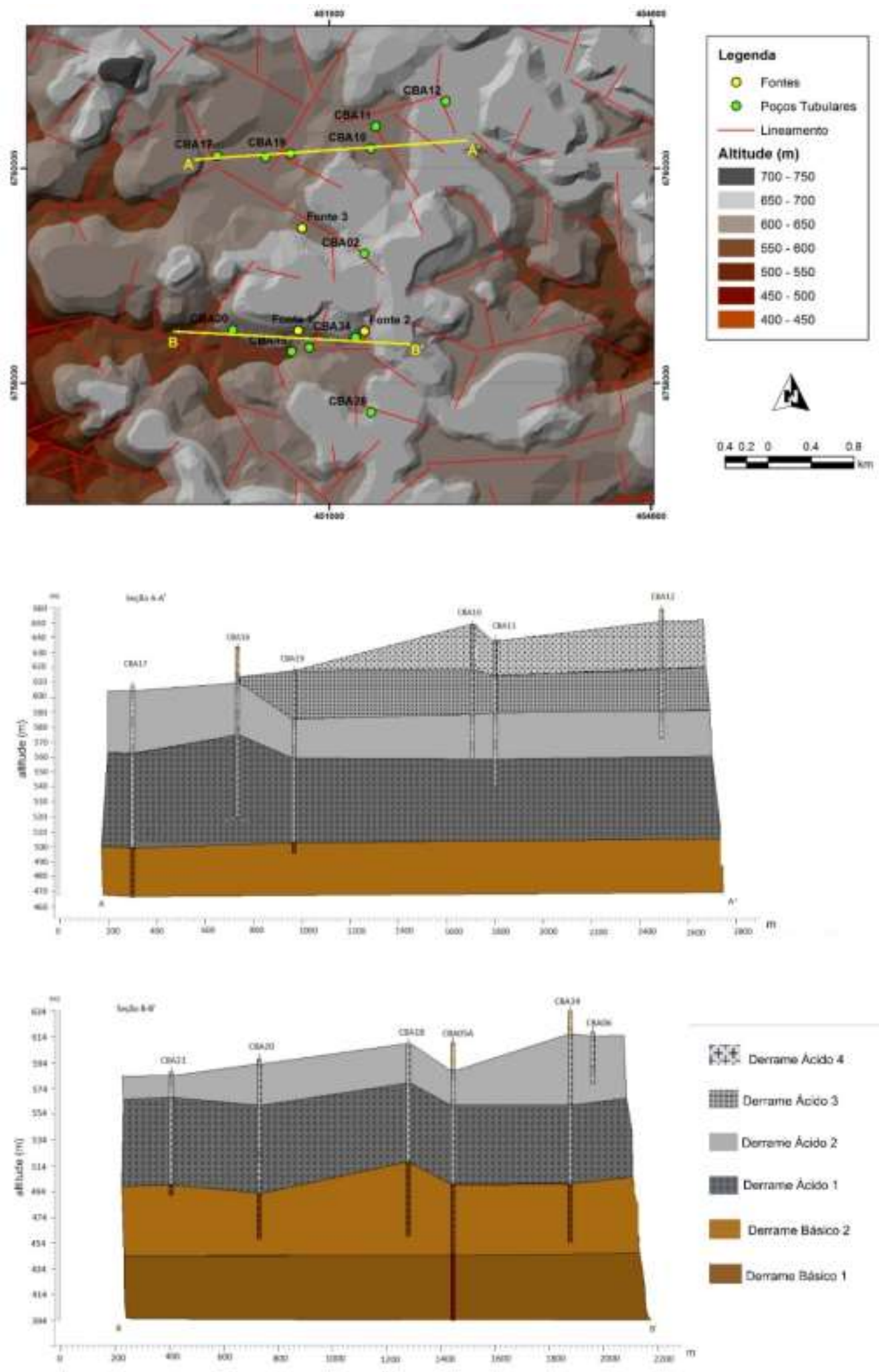

Figura 1 - Seções geológicas, poços e fontes amostrados

Figure 2 - Geological cross-sections, wells and springs sampled 
Relação entre padrões hidroquímicos e as profundidades de fraturas com entradas de água em rochas vulcânicas ácidas da formação serra geral

Tabela 3 - Características dos pontos analisados e respectivas entradas de água

Table 3 - Characteristics of the points analyzed and their water intakes

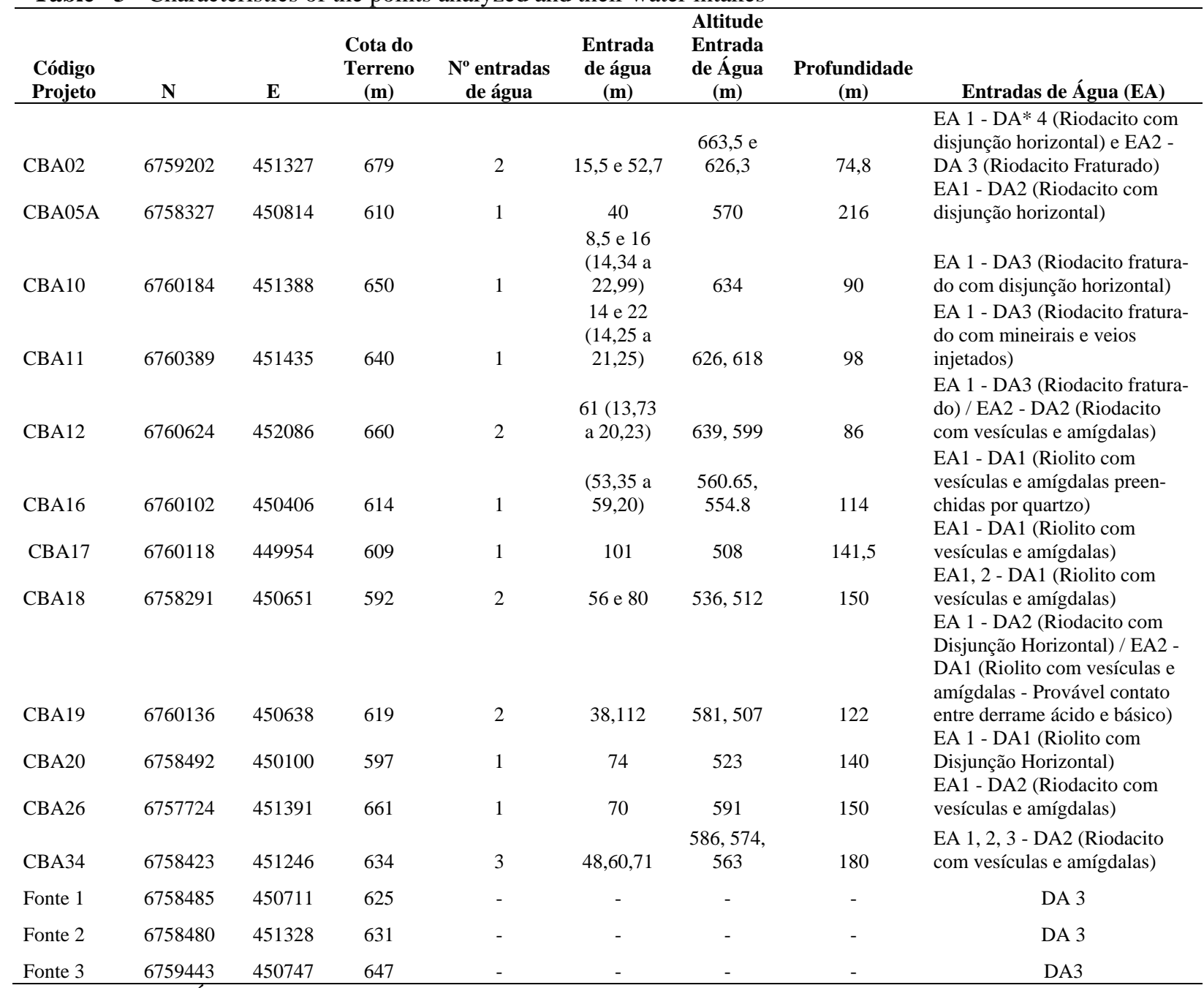

*DA: Derrame Ácido

\subsection{Caracterização Hidroquímica}

As características físico-químicas das águas subterrâneas do Sistema Aquífero Serra Geral (SASG) possuem variações condicionadas pelas características geológicas e hidrogeológicas da região, o que pode ser evidenciada através da caracterização hidroquímica (REGINATO e STRIEDER, 2004).

A circulação das águas subterrâneas nesses aquíferos é condicionada pelo sistema de fraturas e pelas estruturas de resfriamento dos derrames de rochas vulcânicas. Assim, as águas circulam em diferentes níveis de profundidade, em diferentes condições de confinamento e podem apresentar características hidroquímicas variadas.

Os resultados físico-químicos das águas subterrâneas para as duas campanhas realizadas, assim como os valores das principais estatísticas descritivas estão mostradas nas tabelas 4 a 6 . 
BORTOLIN, T. A.; REGINATO, P. A. R.; LEÃO, M. I.; SCHNEIDER, V. E.

Tabela 4 - Valores obtidos na primeira amostragem (Abril 2013)

Table 4 - Values obtained in sample (April 2013)

\begin{tabular}{|c|c|c|c|c|c|c|c|c|c|c|c|c|c|c|c|}
\hline Poço & $\begin{array}{c}\text { Temp } \\
\left({ }^{\circ} \mathrm{C}\right)\end{array}$ & pH & $\begin{array}{c}\text { Cond. } \\
\text { (uS/cm) }\end{array}$ & $\begin{array}{c}\text { Alctotal } \\
(\mathrm{mg} / \mathrm{L})\end{array}$ & $\begin{array}{l}\mathrm{HCO3} \\
(\mathrm{mg} / \mathrm{L}) \\
\end{array}$ & $\begin{array}{c}\mathrm{Ca}^{+2} \\
(\mathrm{mg} / \mathrm{L}) \\
\end{array}$ & $\begin{array}{c}\mathrm{Cl}^{-} \\
(\mathrm{mg} / \mathrm{L}) \\
\end{array}$ & $\begin{array}{c}\mathbf{F}^{-} \\
(\mathbf{m g} / \mathbf{L})\end{array}$ & $\begin{array}{c}\mathbf{F e}^{+2} \\
(\mathrm{mg} / \mathrm{L})\end{array}$ & $\begin{array}{c}\mathrm{Mg}^{+2} \\
(\mathrm{mg} / \mathrm{L}) \\
\end{array}$ & $\begin{array}{c}\mathrm{Mn}^{+2} \\
(\mathrm{mg} / \mathrm{L})\end{array}$ & $\begin{array}{c}\mathbf{K}^{+} \\
(\mathbf{m g} / \mathbf{L}) \\
\end{array}$ & $\begin{array}{c}\mathrm{Na}^{+} \\
(\mathrm{mg} / \mathrm{L})\end{array}$ & $\begin{array}{c}\mathrm{SO}_{4}^{-2} \\
(\mathrm{mg} / \mathrm{L})\end{array}$ & $\begin{array}{c}\text { STD } \\
(\mathbf{m g} / \mathbf{L})\end{array}$ \\
\hline CВА02 & 18,4 & 6,67 & 200 & 59,9 & 73,2 & 20,39 & 10,4 & 0,43 & 0,064 & 3,62 & 0,04 & 4,54 & 13,15 & 3 & 130 \\
\hline CBA05A & 18,88 & 5,87 & 161 & 61,4 & 73,5 & 15,85 & 4,5 & 0,3 & 0,064 & 3,58 & 0,04 & 1,09 & 9,26 & 3 & 161 \\
\hline CBA10 & 18,5 & 5,81 & 112 & 24,4 & 29,3 & 8,87 & 5,5 & 0,82 & 0,064 & 1,76 & 0,04 & 5,4 & 7,41 & 1 & 73 \\
\hline CBA11 & 18.5 & 5,84 & 160 & 38,6 & 46,4 & 11,71 & 3,7 & 0,3 & 0,064 & 1,95 & 0,04 & 3,5 & 6,11 & 1 & 75 \\
\hline CBA12 & 18,62 & 5,85 & 98 & 27,4 & 32,9 & 9,16 & 4,6 & 0,4 & 0,064 & 1,79 & 0,04 & 3,51 & 4,81 & 1 & 64 \\
\hline CBA16 & 19,38 & 6,25 & 154 & 57,4 & 68,9 & 14,29 & 5,2 & 1,35 & 0,067 & 1,83 & 0,04 & 2,82 & 13,7 & 1 & 100 \\
\hline CBA17 & 19,26 & 6,18 & 197 & 75,1 & 91,2 & 21,37 & 5,9 & 0,76 & 0,064 & 1,82 & 0,04 & 1,09 & 15,74 & 4 & 128 \\
\hline CBA18 & 18,52 & 5,89 & 146 & 53,8 & 64,3 & 15 & 3,4 & 0,29 & 0,064 & 1,92 & 0,04 & 2,3 & 9,44 & 1 & 95 \\
\hline CBA19 & 18,9 & 6,13 & 156 & 53,3 & 65,3 & 14,41 & 6,7 & 0,44 & 0,064 & 1,96 & 0,04 & 4,02 & 12,22 & 3 & 102 \\
\hline CBA20 & 18,27 & 5,98 & 144 & 55,3 & 66,8 & 14,76 & 5,9 & 0,63 & 0,064 & 1,87 & 0,04 & 2,3 & 12,96 & 2 & 94 \\
\hline CВА26 & 18,81 & 6,02 & 101 & 35,5 & 40,9 & 8,82 & 3,2 & 1,03 & 0,064 & 1,47 & 0,04 & 2,65 & 9,07 & 1 & 66 \\
\hline CBA34 & 18,63 & 6,28 & 174 & 45,2 & 54,3 & 17,21 & 11,3 & 0,71 & 0,064 & 1,96 & 0,04 & 2,82 & 11,48 & 4 & 113 \\
\hline Fonte 1 & 17,94 & 4,89 & 147 & 6,6 & 7,3 & 9,99 & 7,8 & 0,23 & 0,064 & 3,34 & 0,04 & 4,37 & 10,54 & 6 & 96 \\
\hline Fonte 2 & 18,31 & 6,33 & 127 & 25,4 & 29,3 & 10,22 & 7 & 0,29 & 0,064 & 1,77 & 0,04 & 5,4 & 8,33 & 2 & 82 \\
\hline Fonte 3 & 19,82 & 5,36 & 156 & 5,1 & 5,8 & 8,86 & 11,4 & 0,18 & 0,064 & 3,38 & 0,04 & 7,13 & 10,37 & 10 & 102 \\
\hline
\end{tabular}

Tabela 5 - Valores obtidos na segunda amostragem (Julho 2013)

Table 5 - Values obtained in sample (July 2013)

\begin{tabular}{|c|c|c|c|c|c|c|c|c|c|c|c|c|c|c|c|}
\hline Poço & $\begin{array}{c}\text { Temp } \\
\left({ }^{\circ} \mathbf{C}\right)\end{array}$ & pH & $\begin{array}{c}\text { Cond. } \\
\text { (uS/cm) }\end{array}$ & $\begin{array}{c}\text { Alctotal } \\
(\mathrm{mg} / \mathrm{L})\end{array}$ & $\begin{array}{l}\mathrm{HCO3} \\
(\mathrm{mg} / \mathrm{L})\end{array}$ & $\begin{array}{c}\mathrm{Ca}^{+2} \\
(\mathrm{mg} / \mathrm{L})\end{array}$ & $\begin{array}{c}\mathrm{Cl}^{-} \\
(\mathrm{mg} / \mathrm{L})\end{array}$ & $\begin{array}{c}\mathbf{F}^{-} \\
(\mathrm{mg} / \mathrm{L})\end{array}$ & $\begin{array}{c}\mathrm{Fe}^{+2} \\
(\mathrm{mg} / \mathrm{L})\end{array}$ & $\begin{array}{c}\mathrm{Mg}^{+2} \\
(\mathrm{mg} / \mathrm{L})\end{array}$ & $\begin{array}{c}\mathrm{Mn}^{+2} \\
(\mathrm{mg} / \mathrm{L})\end{array}$ & $\begin{array}{c}\mathbf{K}^{+} \\
(\mathbf{m g} / \mathbf{L})\end{array}$ & $\begin{array}{c}\mathrm{Na}^{+} \\
(\mathrm{mg} / \mathrm{L})\end{array}$ & $\begin{array}{c}\mathrm{SO}_{4}^{-2} \\
(\mathrm{mg} / \mathrm{L})\end{array}$ & $\begin{array}{c}\text { STD } \\
(\mathrm{mg} / \mathrm{L})\end{array}$ \\
\hline СВА02 & 17,28 & 5,78 & 192 & 61,38 & 75,64 & 20,87 & 10,26 & 0,59 & 0,064 & 3,482 & 0,04 & 4,54 & 12,63 & 1 & 125 \\
\hline CBA05A & 17,4 & 6,26 & 157 & 61,4 & 75,6 & 18,91 & 5,79 & 0,81 & 0,064 & 3,58 & 0,04 & 0,92 & 10,17 & 2 & 102 \\
\hline CBA10 & 17,09 & 5,22 & 105 & 26,73 & 32,94 & 8,508 & 5,32 & 0,89 & 0,064 & 1,711 & 0,04 & 5,23 & 7,37 & 1 & 68 \\
\hline CBA11 & 17,2 & 5,62 & 123 & 41,08 & 54,9 & 11,66 & 5,79 & 0,77 & 0,064 & 3,138 & 0,04 & 3,16 & 8,07 & 1 & 80 \\
\hline CBA12 & 17,2 & 5,74 & 123 & 21,78 & 26,84 & 9,768 & 6,08 & 0,57 & 0,064 & 1,73 & 0,04 & 2,99 & 7,37 & 1 & 80 \\
\hline CBA16 & 17,44 & 6,12 & 137 & 64,35 & 79,3 & 16,6 & 2,75 & 0,55 & 0,064 & 1,922 & 0,316 & 2,47 & 10,52 & 1 & 89 \\
\hline CBA17 & 17,3 & 6,17 & 181 & 79,2 & 97,6 & 22,42 & 5,79 & 0,94 & 0,064 & 1,902 & 0,04 & 1,09 & 14,9 & 3 & 118 \\
\hline CBA18 & 17,5 & 6,18 & 151 & 55,44 & 68,32 & 14,905 & 7,88 & 0,88 & 0,064 & 1,997 & 0,04 & 1,96 & 12,1 & 1 & 102 \\
\hline CВА19 & 17,3 & 6,03 & 144 & 59,4 & 73,2 & 14,875 & 4,75 & 0,3 & 0,064 & 3,134 & 0,04 & 3,85 & 10,88 & 1 & 93 \\
\hline CВA20 & 17,11 & 6,28 & 139 & 59,4 & 73,2 & 15,025 & 4,28 & 0,76 & 0,064 & 1,933 & 0,04 & 2,13 & 11,75 & 1 & 90 \\
\hline CBA26 & 16,3 & 6,31 & 104 & 47,52 & 58,56 & 11,09 & 3,51 & 0,77 & 0,064 & 1,481 & 0,04 & 1,27 & 9,82 & 1 & 68 \\
\hline CBA34 & 16,8 & 6,16 & 163 & 47,02 & 57,95 & 18,21 & 10,92 & 0,37 & 0,064 & 1,879 & 0,04 & 2,65 & 10,88 & 1 & 106 \\
\hline Fonte 1 & 15 & 5,39 & 124 & 6,93 & 8,54 & 8,85 & 9,88 & 0,38 & 0,064 & 3,228 & 0,04 & 3,85 & 9,47 & 5 & 81 \\
\hline Fonte 2 & 11,22 & 6,05 & 108 & 25,47 & 31,72 & 11,07 & 8,55 & 0,03 & 0,064 & 1,708 & 0,04 & 4,89 & 9,3 & 1 & 70 \\
\hline Fonte 3 & 17,11 & 5,15 & 135 & 4,45 & 5,49 & 7,676 & 10,83 & 0,4 & 0,117 & 3,322 & 0,04 & 6,44 & 9,47 & 8 & 88 \\
\hline
\end{tabular}


Tabela 6 - Estatísticas descritivas dos parâmetros analisados

Table 6 - Descriptive statistics of the parameters analyzed

\begin{tabular}{cccccc}
\hline Parâmetro & Número de casos & Mínimo & Máximo & Média & Desvio-Padrão \\
\hline Alctotal (mg/L) & 30 & 4,45 & 79,2 & 42,87 & 21,14 \\
$\mathbf{H C O 3 ~ ( m g / L ) ~}$ & 30 & 5,49 & 97,6 & 52,31 & 26,01 \\
$\mathbf{C a}^{+2}(\mathbf{m g} / \mathbf{L})$ & 30 & 7,68 & 22,42 & 13,71 & 4,37 \\
$\mathbf{C l}^{-}(\mathbf{m g} / \mathbf{L})$ & 30 & 2,75 & 11,4 & 6,63 & 2,67 \\
$\mathbf{M g}^{+2}(\mathbf{m g} / \mathbf{L})$ & 30 & 1,47 & 3,62 & 2,34 & 0,77 \\
$\mathbf{K}^{+}(\mathbf{m g} / \mathbf{L})$ & 30 & 0,92 & 7,13 & 3,35 & 1,63 \\
$\mathbf{N a}^{+}(\mathbf{m g} / \mathbf{L})$ & 30 & 4,81 & 15,74 & 10,31 & 2,51 \\
$\mathbf{S O}^{-2}(\mathbf{m g} / \mathbf{L})$ & 30 & 1 & 10 & 2,4 & 2,27 \\
$\mathbf{F}^{-}(\mathbf{m g} / \mathbf{L})$ & 30 & 0,03 & 1,35 & 0,57 & 0,30 \\
$\mathbf{F e}^{+2}(\mathbf{m g} / \mathbf{L})$ & 30 & 0,064 & 0,117 & 0,066 & 0,01 \\
$\mathbf{M n}^{+2}(\mathbf{m g} / \mathbf{L})$ & 30 & 0,04 & 0,316 & 0,049 & 0,05 \\
$\mathbf{p H}$ & 30 & 4,89 & 6,67 & 5,93 & 0,40 \\
$\mathbf{C o n d}(\mathbf{u S} / \mathbf{c m})$ & 30 & 98 & 200 & 143,97 & 28,27 \\
$\mathbf{S T D}^{(\mathbf{m g} / \mathbf{L})}$ & 30 & 64 & 161 & 94,7 & 22,33 \\
$\mathbf{T e m p}\left({ }^{\circ} \mathbf{C}\right)$ & 30 & 11,22 & 19,82 & 17,64 & 1,61 \\
\hline
\end{tabular}

Em geral, as águas do Aquífero Serra Geral na região de Carlos Barbosa apresentam concentrações variáveis de cálcio, magnésio e sódio e, pequenas concentrações de cloretos e sulfatos, como também encontradas por Bortolin et al. (2014). A concentração média de Cálcio, de $13,71 \mathrm{mg} / \mathrm{L}$, está diretamente relacionada ao arcabouço químico-mineralógico do aquífero, pois reflete a remoção do cálcio dos plagioclásios e minerais ferromagnesianos dos basaltos. A solubilidade do $\mathrm{Ca}^{2+}$ em águas naturais está vinculada à presença de espécies carbônicas dissolvidas como $\mathrm{H}_{2} \mathrm{CO}_{3}, \mathrm{HCO}_{3}^{-}$e $\mathrm{CO}_{3}{ }^{-2}$ (MOCELIN e FERREIRA, 2009).

O principal ânion presente nas águas subterrâneas do SASG na área de estudo é o íon bicarbonato, proveniente das reações de equilíbrio da série carbonática, iniciada nas áreas de recarga com a dissolução de $\mathrm{CO}_{2}$ presente nos solos e na água da chuva ou como produto da hidrólise de silicatos do basalto o que acaba caracterizando a maior parte das águas como bicarbonatada (BITTENCOURT et al., 2003; GASTMANS, 2007). Apesar disso, a concentração de bicarbonato é baixa, quando comparado por exemplo às águas do Sistema Aquífero Guarani, apresentando valores que variam de 5,49 a $97,6 \mathrm{mg} / \mathrm{L}$.
$\mathrm{O}$ pH das amostras de água subterrânea coletadas indica uma preponderância de águas ácidas, com valores que variam de 4,89 a 6,67; sólidos totais dissolvidos (STD) de 64 a $161 \mathrm{mg} / \mathrm{L}$ e $\mathrm{Na}^{+}$de 4,81 a $15,74 \mathrm{mg} / \mathrm{L}$, valores baixos, devido principalmente às entradas de água estarem associadas aos derrames de rochas vulcânicas ácidas e serem pouco profundas. Estes valores representam características de águas com pouco tempo de residência com recarga relacionada às precipitações pluviométricas através do manto de intemperismo (HAUSMANN, 1966; LISBOA, 1996).

O ferro, comum nos óxidos de ferro (hematita e magnetita) e o manganês apresentaram concentrações inferiores a 0,117 $\mathrm{mg} / \mathrm{L}$ e $0,316 \mathrm{mg} / \mathrm{L}$, respectivamente. As reduzidas concentrações de cloreto e sulfatos encontradas, em geral inferiores a $6 \mathrm{mg} / \mathrm{L}$ e 4 $\mathrm{mg} / \mathrm{L}$, respectivamente, com exceção dos poços CBA02, CBA34 e fontes, que possuem concentrações superiores a $7 \mathrm{mg} / \mathrm{L}$ de cloretos, são explicadas devido às rochas ígneas serem pobres em cloretos e sulfatos.

Em relação ao íon potássio, verificase que este é pouco presente nas amostras, variando de 0,92 a 7,13 $\mathrm{mg} / \mathrm{L}$ sendo que a maior parte do potássio liberado por hidrólise 
é logo adsorvido por minerais argilosos (MANASSES et al., 2007).

A condutividade elétrica das águas subterrâneas é o parâmetro que apresenta relação direta com a mineralização das águas, podendo ser indicativo de sentidos de fluxo das águas subterrâneas e grau de confinamento das mesmas (GASTMANS, 2007). No caso da região do SASG analisado, as amostras apresentam condutividade variando de 98 a $200 \mu \mathrm{S} / \mathrm{cm}$.

A classificação das águas subterrâneas foi realizada através do uso do diagrama Piper, sendo que as duas amostragens realizadas indicaram a ocorrência de águas bicarbonatadas cálcicas ou magnesianas para os poços tubulares e uma fonte. Já a água de duas fontes foi classificada como sulfatada ou cloretada cálcica ou magnesiana (cloretadas mistas). Pela concentração de cátions identificou-se que as águas são cálcicas ou mistas.

A ocorrência desse tipo de água está de acordo com os estudos do Sistema Aquífero Serra Geral realizados por Bittencourt (1978), Fraga (1992), Nanni (2008), Athayde et al. (2012), e estudos regionais realizados por Lisboa (1996), Betiollo (2006), Reginato et al. (2013), Nanni et al. (2013) e Bortolin et al. (2014), sendo que a fonte dos elementos cálcio, magnésio e sódio está relacionada com os silicatos presentes nas diferentes rochas vulcânicas.

Conforme Lisboa (1996) as águas que circulam no SASG tendem a apresentar uma relação onde o $\mathrm{Ca}>\mathrm{Mg}>\mathrm{Na}$ predomina e um enriquecimento de cálcio e magnésio do topo (rochas ácidas) para a base (rochas básicas). Segundo Machado e Freitas (2000) esse padrão está associado às primeiras fases de evolução geoquímica das águas que circulam no SASG. Bittencourt et al. (2003) afirmam que as águas bicarbonatadas cálcicas são as águas típicas do SASG, sendo o cálcio o cátion mais abundante, proveniente da alteração de plagioclásios e minerais ferromagnesianos dos basaltos.

Segundo Manasses et al. (2007), o campo das águas bicarbonatadas cálcicas possui um controle litoquímico, já que suas características químicas estão relacionadas em boa parte com os processos de intemperismo que atuam sobre as rochas vulcânicas, característica bem comum em águas continentais relativamente diluídas.

Reginato et al. (2013) explicam que, ainda que as águas tenham a mesma classificação estas podem apresentar concentrações distintas para os elementos cálcio, magnésio e sódio por circularem por aquíferos fraturados que estão associados a diferentes rochas vulcânicas e profundidades variadas.

A análise do diagrama de Schoeller (Figura 3) indica a existência de um comportamento hidroquímico com pequenas variações nas concentrações dos íons analisados.

As variações mais significativas estão relacionadas às concentrações de magnésio, sódio, cloro e sulfato e podem ser explicadas pela ocorrência de diferentes entradas de água, localizadas em profundidades distintas de diferentes derrames de rochas vulcânicas ácidas. 


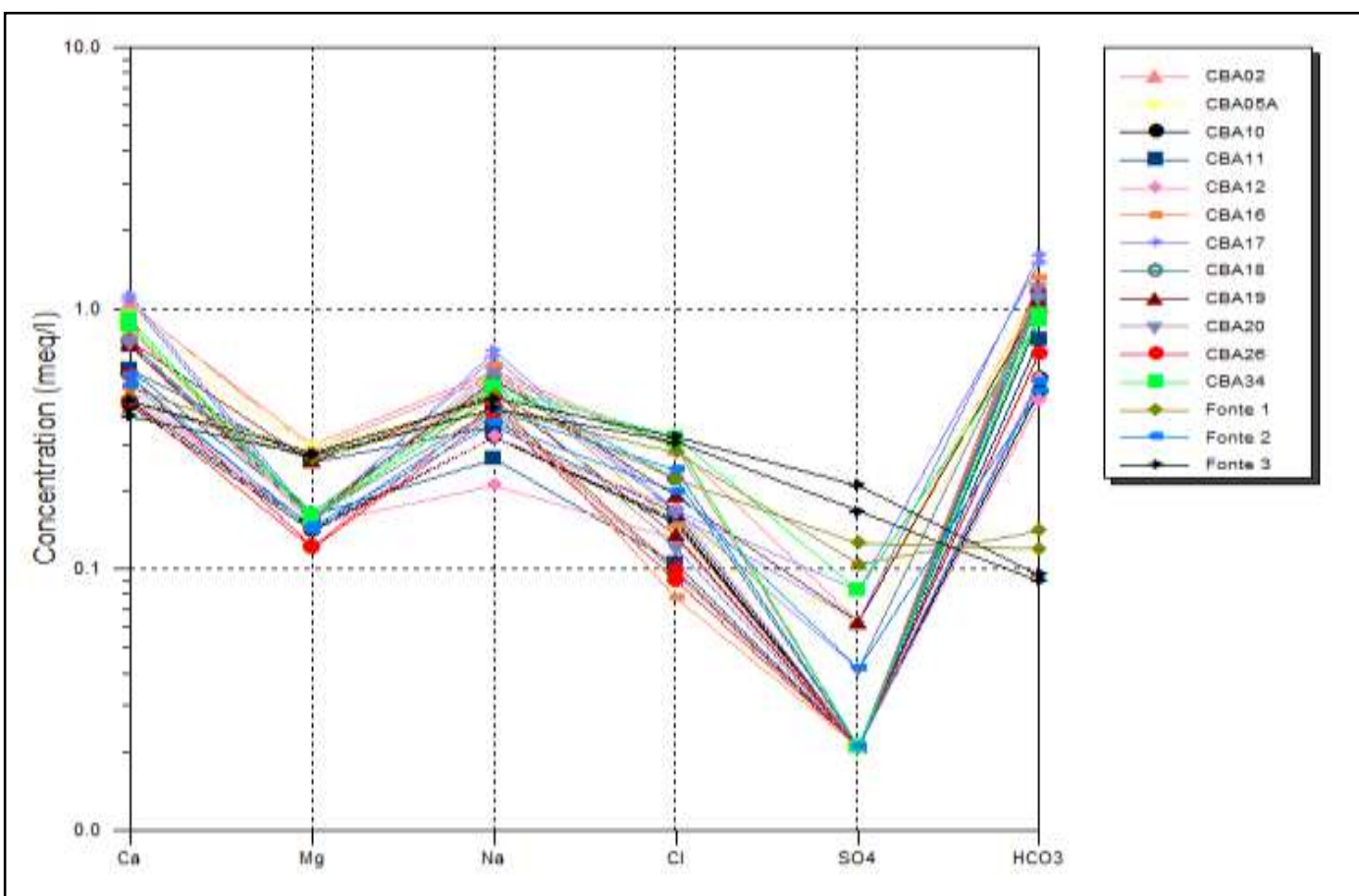

Figura 3 - Diagrama de Schoeller das amostras de água subterrânea do SASG na área de estudo Figure 3 - Schoeller Diagram of groundwater samples from the SGAS in the study area

\subsection{Análise estatística}

De acordo com a aplicação do teste estatístico de Kruskal-Wallis, a um nível de significância de 5\%, constatou-se que os parâmetros condutividade elétrica, sólidos totais dissolvidos, alcalinidade e os íons de cálcio, bicarbonato, magnésio, potássio e sódio apresentam diferenças significativas entre os poços e fontes analisadas, uma vez que possuem $p$-value inferior a 0,05 , como apresenta a Tabela 7.

Estas diferenças dos parâmetros e íons analisados entre os poços e fontes amostradas podem ser visualizadas nos gráficos da Figura 4.

Tabela 7 - Resultados do teste de Kruskal-Wallis

Table 7 - Kruskal-Wallis Test Results

\begin{tabular}{ccc}
\hline Parâmetro & Kruskal-Wallis & p-value \\
\hline Temperatura & 5,227 & 0,982 \\
pH & 20,171 & 0,125 \\
Condutividade & 25,314 & 0,032 \\
Alctotal & 27,983 & 0,015 \\
HCO $^{\mathbf{3}}$ & 27,837 & 0,015 \\
$\mathbf{C a}^{+2}$ & 27,474 & 0,017 \\
$\mathbf{C l}^{-}$ & 23,042 & 0,06 \\
$\mathbf{F}^{-}$ & 18,258 & 0,195 \\
$\mathbf{F e}^{+2}$ & 13,466 & 0,49 \\
$\mathbf{M g}^{+2}$ & 27,564 & 0,016 \\
$\mathbf{M n}^{+2}$ & 14 & 0,45 \\
$\mathbf{K}^{+}$ & 28,36 & 0,013 \\
$\mathbf{N a}^{+}$ & 26,053 & 0,025 \\
$\mathbf{S O}^{-2}$ & 22,193 & 0,075 \\
$\mathbf{S T D}^{-2}$ & 26,147 & 0,025 \\
\hline
\end{tabular}


BORTOLIN, T. A.; REGINATO, P. A. R.; LEÃO, M. I.; SCHNEIDER, V. E.

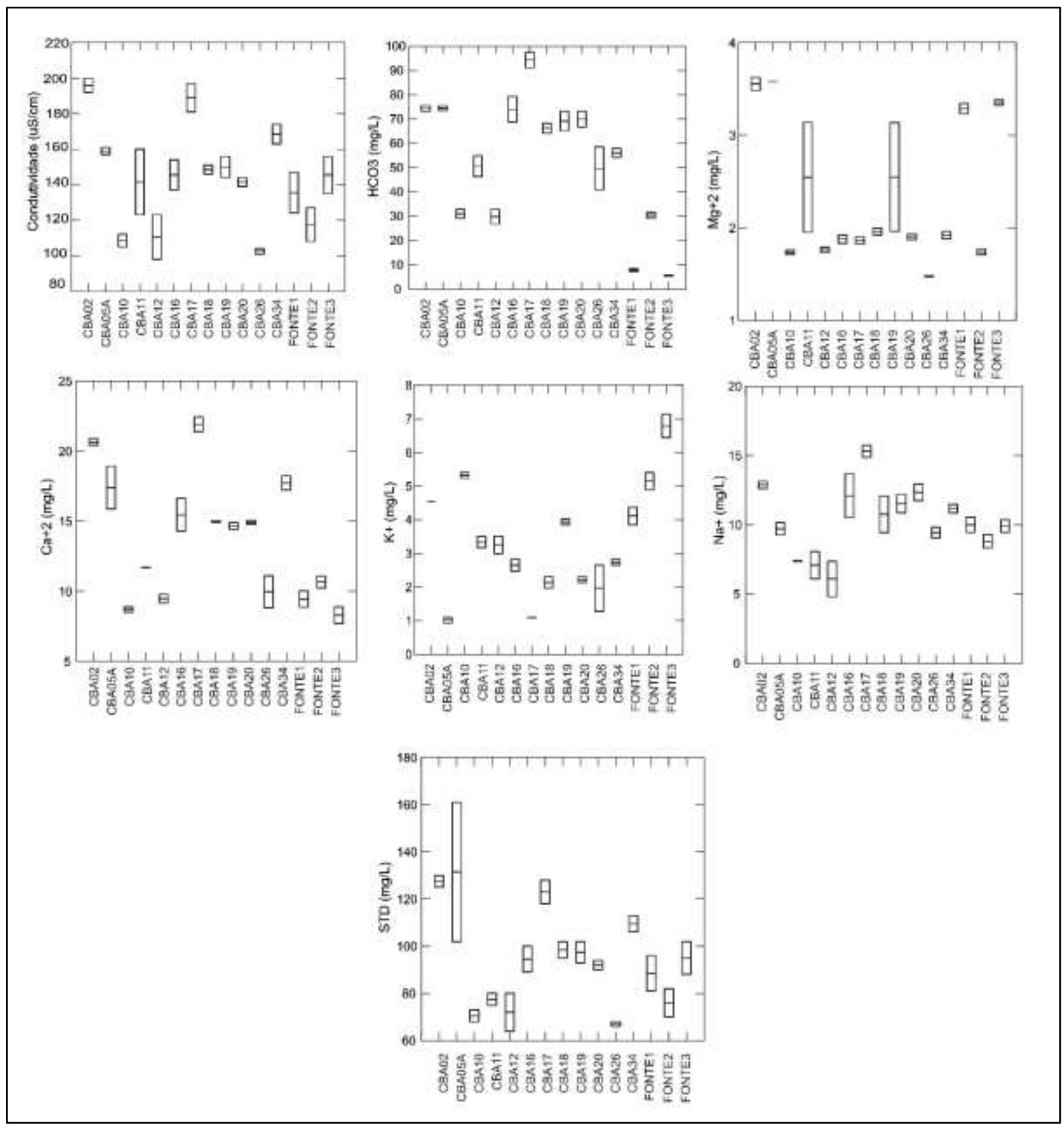

Figura 4 - Gráficos box-plot de parâmetros e íons que possuem diferença significativa nos poços e fontes analisados Figure 4 - Graphics box-plot parameters and ions that have a significant difference in the wells and sources analyzed

A partir da identificação destas diferenças buscou-se verificar a relação entre os poços/fontes e suas entradas de água, verificando a ocorrência de agrupamentos entre os pontos amostrados devido às suas características hidroquímicas. A análise dos agrupa- mentos forneceu o dendograma apresentado na Figura 5, indicando a existência de 3 grupos de águas, distinguidos pela distância de ligação entre eles, conforme descritos a seguir: 


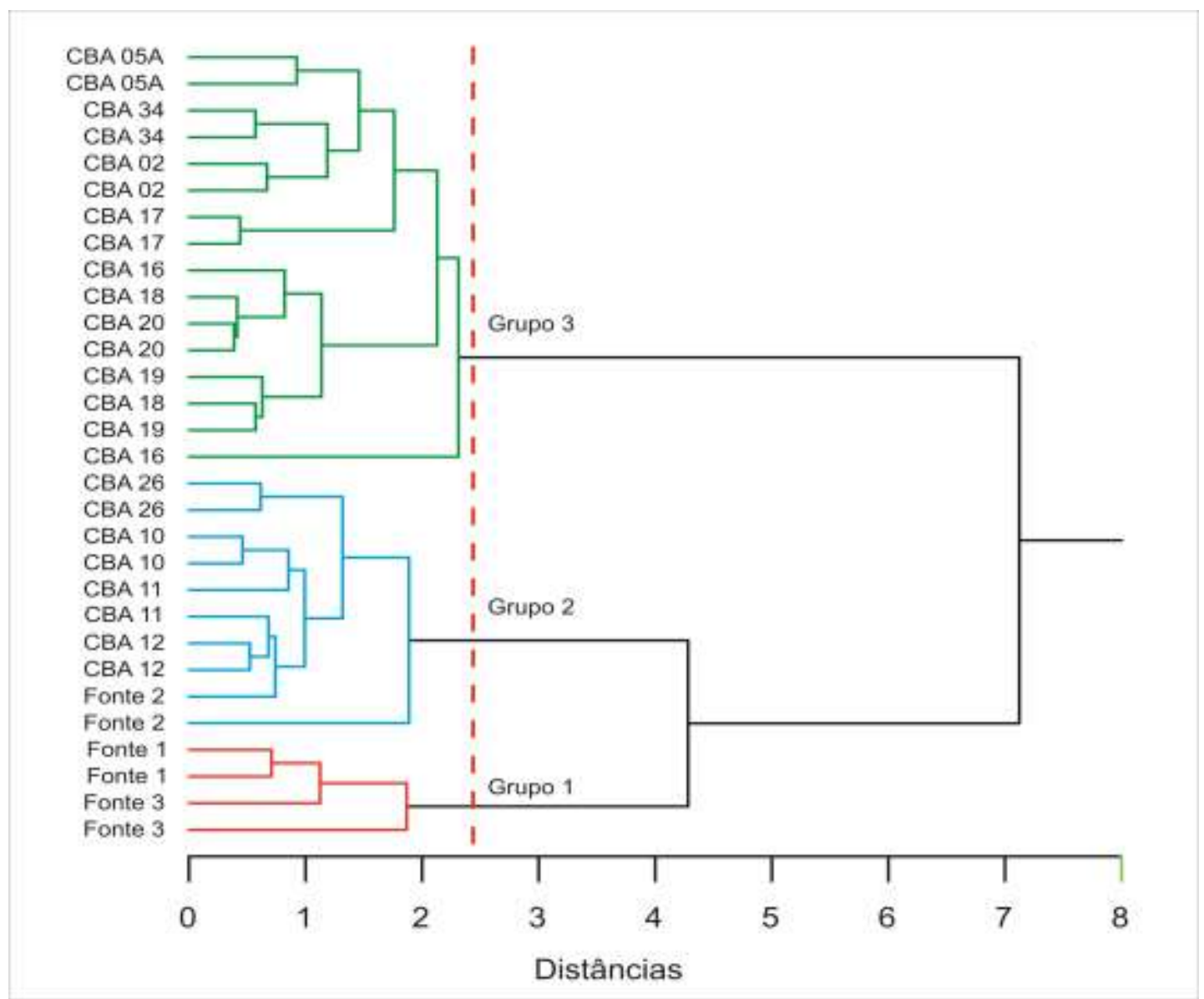

Figura 5 - Dendograma das amostras de águas subterrâneas do SASG na área de estudo

Figure 5 - Dendogram samples of underground SGAS waters in the study area

Grupo 01: Grupo de amostras de águas de fontes que apresentaram uma característica diferenciada em relação a categorização obtida pelo diagrama Piper (fonte 1 e fonte 3 ). Este grupo representa águas com baixo grau de mineralização, provenientes da zona de recarga de aquíferos. Entende-se que, apesar de estes pontos apresentarem características de águas sulfatadas/cloretadas e cálcicas/magnesianas, estas fontes pertencem ao aquífero fraturado, por serem fontes de encostas e por possuírem características hidroquímicas diferentes de águas do aquífero granular (freático livre), como descrita por Reginato et al. (2012).

Ainda que estes pontos apresentem baixa alcalinidade, e concentrações de cálcio, sódio, estes e outros valores como de magnésio, potássio e sólidos totais dissolvidos são maiores do que valores encontrados em aquíferos granulares da região. Essas águas apresentam uma concentração maior de sulfato e cloreto cuja origem pode estar relacionada a diferentes fatores como um maior tempo de retenção na caixa de armazenamento, processos de degradação, contaminação devido a presença de sistemas de esgotamento sanitário do tipo fossas sépticas ou ainda entrada da água que escoa pela superfície do terreno após a precipitação.

Grupo 02: Grupo formado por amostras de poços onde a entrada de água é inferior a 30 metros, localizado no derrame ácido 3 , em altitudes entre 620 e 649 metros, sendo que a água circula por meio de riodacitos fraturados com disjunções horizontais (CBA 10, CBA 12) e, alguns poços, possuem na profundidade da entrada de água, minerais e veios injetados (CBA 11). Neste grupo também entrou a fonte 2, com características muito similares ao poço CBA12. Os poços pertencentes a este grupo apresentaram menor valor de $\mathrm{pH}$ (média de 5,7), menor concentração de $\mathrm{HCO}_{3}$ (média de $28,9 \mathrm{mg} / \mathrm{L}$ ), $\mathrm{Na}^{+}$(média de 7,34 mg/L), $\mathrm{Ca}^{+2}$ (média de 
$11,1 \mathrm{mg} / \mathrm{L})$ e sólidos totais dissolvidos, com média de 74 mg/L (Figura 4).

Essas características podem ser explicadas pela existência de uma entrada de água menos profunda, o que contribui para uma maior recarga e circulação da água subterrânea rasa, favorecendo assim a renovação e a baixa concentração de elementos. Os componentes dissolvidos estão diretamente relacionados ao tempo de residência da água nos aquíferos e às maiores concentrações de sólidos dissolvidos. Valores baixos de STD e íons presentes nas amostras analisadas podem refletir um tempo de residência potencialmente curto, limitando o tempo de interação água-rocha.

Nestas águas mais ácidas são observados menores valores de STD. À medida que a água subterrânea se move no aquífero, ocorre redução da acidez devido às reações de intemperismo químico, sendo estabelecido o equilíbrio iônico e ocorre aumento na quantidade de sólidos dissolvidos na solução de lixiviação. Dessa forma, águas com maior teor de STD apresentam maior valor de $\mathrm{pH}$.

A exceção deste grupo, refere-se ao poço CBA 26, o qual apresenta características muito próximas ao CBA 10, em termos de STD, condutividade, cálcio e alcalinidade, porém possui entrada de água próxima a 70 metros.

A circulação de água nesta profundidade está restrita a diaclases ou regiões próximas a contato de derrames onde ocorrem rochas vesiculares a amigdaloides. Neste sentido, o poço CBA 26 possui sua entrada de água localizada entre o Derrame Ácido 2 e Derrame Ácido 3. As características químicas da água são mais semelhantes ao grupo 2, exceto em termos de concentração de sódio e $\mathrm{pH}$, cujos valores são maiores, apresentando uma média respectiva de $9,45 \mathrm{mg} / \mathrm{L}$ de sódio e pH de 6,17, e concentração menor de $\mathrm{Mg}^{+2}$, correspondendo a $1,47 \mathrm{mg} / \mathrm{L}$, possível reflexo da entrada de água ser mais profunda.

Grupo 03: Amostras provenientes de poços com entrada de água mais profunda, que varia de 50 a 112 metros, localizada no derrame ácido 1, em altitudes entre 500 e 561 metros, com presença de riolitos, em sua maior parte preenchido por vesículas e amígdalas. Os poços agrupados são: CBA 16, CBA17 CBA 18, CBA 19 e CBA20. Além disso, 2 poços estão localizados no derrame ácido 2, com presença de riodacito com disjunções horizontais (CBA 05, CBA 34) e um poço com duas entradas de água, uma no derrame ácido 4 e outro no derrame ácido 3 (CBA 02).

As amostras de água coletadas nestes poços apresentam semelhança entre si em relação a condutividade que varia entre $140 \mathrm{e}$ $200 \mathrm{uS} / \mathrm{cm}$, superior ao do grupo 2 , devido às profundidades das entradas de água, as quais são mais profundas, possivelmente com maior tempo de interação água-rocha possibilitando maior dissolução de íons, como cálcio, sódio, magnésio.

A água com maior tempo de contato com a rocha permite dissolução maior dos minerais, especialmente os plagioclásios cálcicos e sódicos, os quais são liberados mais rapidamente que o potássio. Dessa forma, são observados valores maiores de cálcio e sódio, com média de $17,19 \mathrm{mg} / \mathrm{L}$, e $12 \mathrm{mg} / \mathrm{L}$, respectivamente, verificando enriquecimento destes íons em função do confinamento. Ao mesmo tempo observa-se concentrações de bicarbonato que variam de 65 a $80 \mathrm{mg} / \mathrm{L}$, valor quase 2,5 vezes superior ao grupo com entradas de água em até 30 metros. Isso pode estar relacionado a um maior grau de confinamento ou a presença de minerais de carbonato que ocorrem preenchendo fraturas ou amígdalas. A concentração maior de minerais reflete em um maior valor de sólidos totais dissolvidos, em média $100 \mathrm{mg} / \mathrm{L}$, e um $\mathrm{pH}$ maior, com média de 6,1 .

O poço CBA 17 apresentou as maiores concentrações de todas as amostras em termos de cálcio, sódio e bicarbonatos, com médias de $21,9 \mathrm{mg} / \mathrm{L}, 15,32 \mathrm{mg} / \mathrm{L}$ e 94,4 $\mathrm{mg} / \mathrm{L}$ respectivamente, exemplificando o fato que com entradas de água mais profundas, maior é a concentração destes íons. Dos casos amostrados, este poço apresenta a segunda maior profundidade, inferior apenas ao CBA19. Entretanto, ao observar as características hidroquímicas do CBA19, verifica-se que as concentrações são inferiores ao 
CBA17, resultado possível de mistura de águas de outra entrada que este poço possui.

A particularidade deste grupo está associada aos maiores valores de condutividade elétrica, pH e STD quando comparados com os poços dos outros grupos, além de cálcio, resultado da presença de calcita nas vesículas e amígdalas dos derrames, sendo este mineral um controlador de cálcio nas águas, principalmente com $\mathrm{pH}$ mais elevado.

Na Figura 6, onde podem ser visualizados exemplos das geometrias do diagrama Stiff encontradas em cada grupo de poços nas duas coletas, é possível identificar a diferença de águas localizadas em um mesmo derrame ácido.

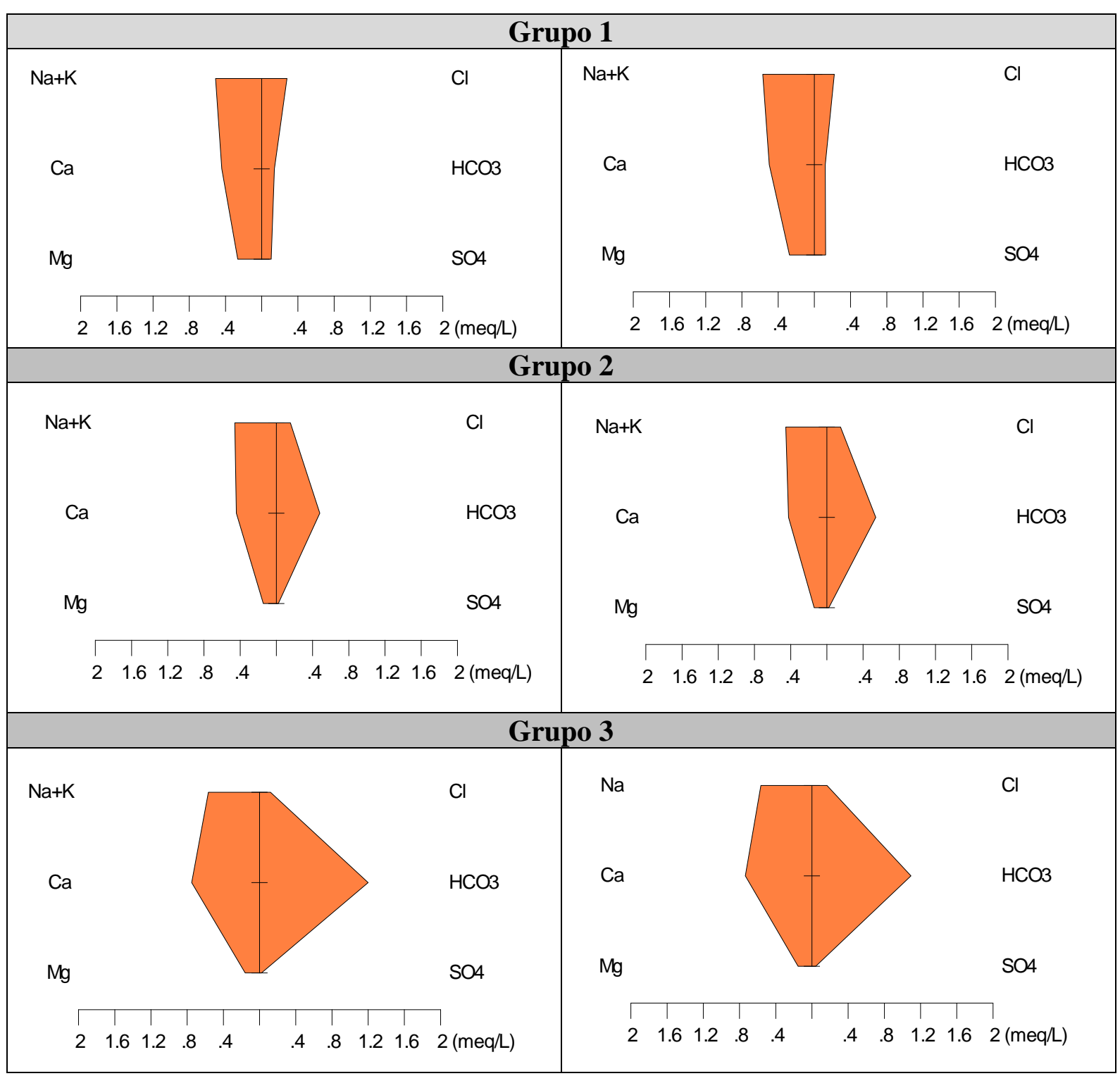

Figura 6 - Exemplos de geometrias típicas observadas no Diagrama de Stiff referente aos três grupos das amostras de água subterrânea do SASG na área de estudo

Figure 6 - Examples of typical geometries observed in Stiff diagram referring to three groups of groundwater samples from the SGAS in the study area 
Apesar das amostras apresentarem uma feição geométrica semelhante, características das águas bicarbonatadas cálcicas ou magnesianas, com exceção do Grupo 1, pode-se perceber uma variação na concentração dos íons, quando as entradas de água estão localizadas em profundidades e derrames diferentes. Entretanto, localmente, verifica-se que os diversos derrames em sequência proporcionam a observação de pequenas diferenças, as quais são verificadas pelo agrupamento de poços que possuem entradas de água localizadas em profundidades semelhantes, mesmo estando em fraturas diferen- tes.

Embora os poços tubulares selecionados tenham sido perfurados na sequência de rochas vulcânicas ácidas, as estruturas tectônicas encontradas nas litologias cortam diferentes derrames e podem proporcionar diferentes padrões de circulação, dando origem a padrões hidroquímicos e razões iônicas distintas. Essas características podem ser melhor visualizadas na Figura 7, a qual apresenta um modelo conceitual hidroquímico para o sistema aquífero SASG em derrames ácidos da área de estudo.

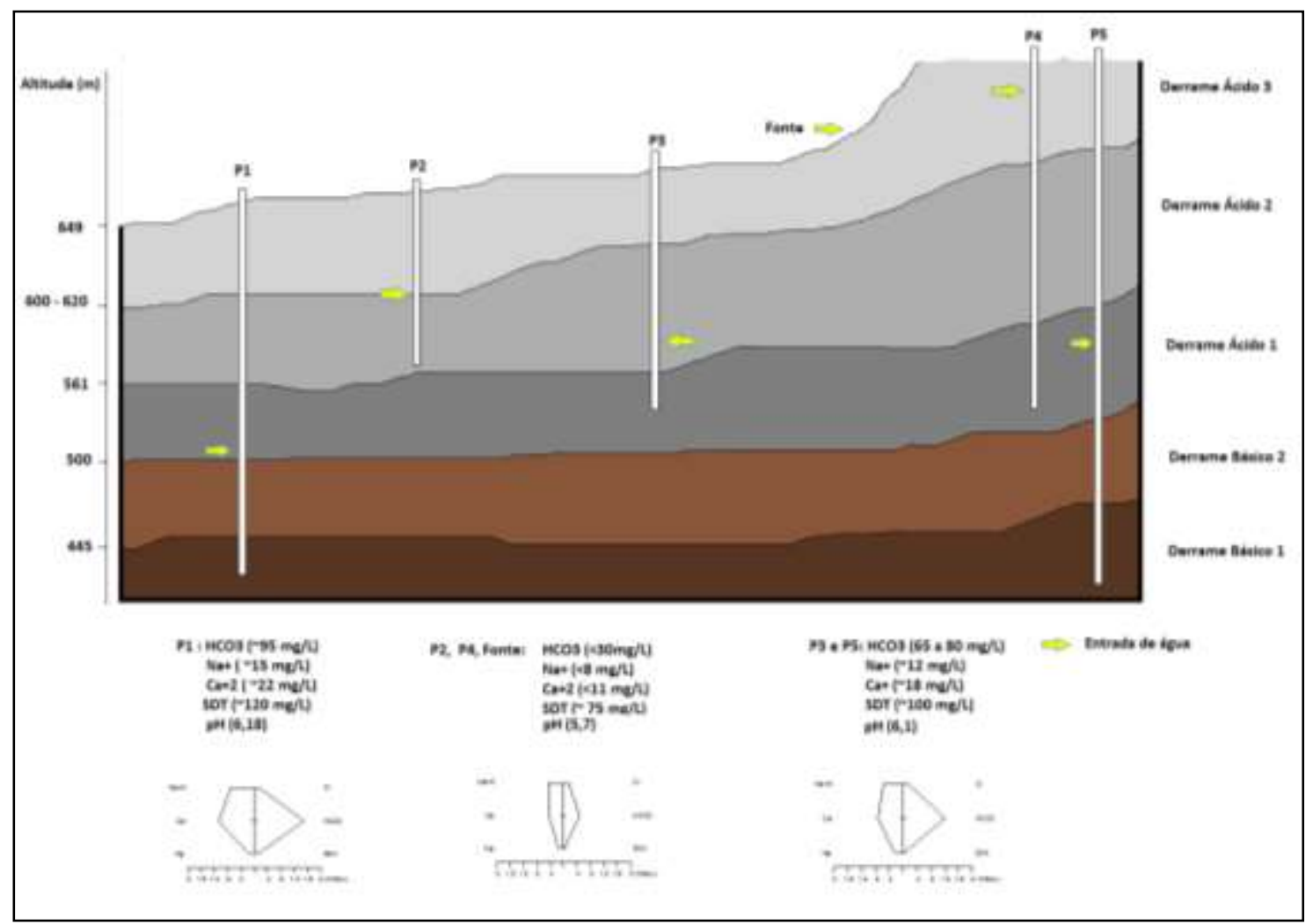

Figura 7 - Modelo conceitual hidroquímico do SASG para a área de estudo

Figure 7 -SGAS Hydrochemical conceptual model for the study area

De acordo com o modelo conceitual hidroquímico, poços com entrada de água mais rasa, representados pelos pontos $\mathrm{P} 2, \mathrm{P} 4$ e Fonte, possuem menores concentrações dos íons analisados, bem como pH mais ácido, resultante de uma rápida circulação que não permite o estabelecimento do equilíbrio químico. Ao aumentar a profundidade da entrada de água, o tempo de residência da água que infiltrou torna-se maior, permitindo que ocorram processos de interação águarocha, aumentando a concentração dos íons, característica dos poços P1, P3 e P5.

$\mathrm{O}$ fato de ter variações entre concentrações iônicas em poços localizados em um mesmo intervalo de profundidades de entradas de água pode estar associado às mineralizações, bem como os poços podem ter interações com águas que circulam em maior profundidade. 


\section{CONSIDERAÇÕES FINAIS}

$\mathrm{Na}$ região abrangida pelo município de Carlos Barbosa há ocorrência de aquíferos fraturados que fazem parte do Sistema Aquífero Serra Geral e que estão localizados nos derrames de rochas ácidas da Formação Serra Geral.

Pelas amostragens realizadas, verificou-se a existência de um comportamento hidroquímico geral com pequenas variações nas concentrações dos íons analisados, relacionadas às concentrações de magnésio, sódio, cloro e sulfato e podem ser explicadas pela ocorrência de diferentes entradas de água, localizadas em profundidades distintas de diferentes derrames de rochas vulcânicas ácidas.

De acordo com os parâmetros analisados e as entradas de água em diferentes profundidades pode-se agrupar os pontos amostrados em 3 grupos distintos: Grupo 1, característico das fontes que apresentam águas sulfatadas ou cloretadas, cálcicas ou magnesianas; Grupo 2, agrupando poços com entrada de água menos profunda, contribuindo para uma maior recarga e circulação da água subterrânea rasa, favorecendo assim a renovação e a baixa concentração de íons; Grupo 3, agrupando poços com entrada de água mais profunda, as quais possuem maior tempo de contato com a rocha influenciando a maior intemperização dos minerais. Como consequência, obteve-se uma maior concentração de íons como cálcio, sódio, bicarbonatos e parâmetros como condutividade e sólidos dissolvidos totais.

A caracterização hidroquímica indica que as águas subterrâneas dessa região apresentam baixo grau de mineralização e baixo tempo de residência, sendo que as exceções foram encontradas em poços que possuíam entradas de água mais profundas.

Este trabalho contribuiu no conhecimento hidroquímico do Sistema Aquífero Serra Geral, especificamente em uma região cujo abastecimento de água é realizado somente através deste aquífero. O estudo auxiliou na verificação da existência de diferenças no padrão hidroquímico do aquífero fraturado permitindo um melhor entendimento das características deste sistema, facilitando a compreensão quanto aos padrões de circulação, recarga e alterações hidroquímicas.

\section{REFERÊNCIAS}

ALMEIDA, J. R. F. Análise estatística multivariada e modelo geoquímico inverso no estudo da qualidade da água subterrânea na bacia do Forquilha em Quixeramobim - Ceará. 2009. 144 f. Dissertação (mestrado) - Universidade Federal do Ceará, Programa de Pós-graduação em Engenharia Civil, Fortaleza, 2009.

ATHAYDE, G. B.; ATHAYDE, C. V. M.; ROSA FILHO, E. F. Compartimentação hidroestrutural e aptidões químicas do Sistema Aquífero Serra Geral no estado do Paraná. Revista Brasileira de Geociências, 42, Supl. 1, p. 167-185, 2012.

BETIOLLO, L. M. Caracterização estrutural, hidro-geológica e hidroquímica dos sistemas aquíferos Guarani e Serra Geral no nordeste do Rio Grande do Sul, Brasil. 2006. 117 f. Dissertação (mestrado). Instituto de Geociências, Programa de Pós-Graduação em Geociências, Universidade Federal do Rio Grande do Sul. Porto Alegre, 2006.

BITTENCOURT, A. V. L. Sólidos hidrotransportados na bacia hidrográfica do rio Ivaí: Aplicação de balanços hidrogeoquímicos na compreensão da evolução de processos da dinâmica externa. 1978. 291 p. Tese (doutorado). Instituto de Geociências, Universidade de São Paulo (USP). São Paulo, 1978.

BITTENCOURT A.V.L., ROSA FILHO E. F., HINDI E. C., BUCHMANN FILHO A. C. A influência dos basaltos e de misturas com águas de aquíferos sotopostos nas águas subterrâneas do Sistema Aquífero Serra Geral na bacia do rio Piquiri, Paraná BR. Rev. Águas Subterrâneas, 17, p. 67-76, 2003.

BORTOLIN, T. A., REGINATO, P. A. R., LEÃO, M. I., \& SCHNEIDER, V. E. Hidrogeologia e hidroquímica dos aquíferos fraturados associados às rochas vulcânicas ácidas no Município de Carlos Barbosa (RS). Ambiente \& Água-An Interdisciplinary Journal of Applied Science, 9(1), 55-67, 2014. 
CORRAR, L. J.; PAUlO, E.; FILHO, J. M. D. Análise Multivariada para os Cursos de Administração, Ciências Contábeis e Economia. 1. ed. 2. reimpr. São Paulo: Atlas, 2009. 541 p.

CPRM. Mapeamento geológico integrado da bacia hidrográfica do Guaíba: carta geológica: FolhaSH.22-V-D - Caxias do Sul. Companhia de Pesquisas de Recursos Minerais. Porto Alegre (Brasil). 1 mapa color. Escala 1:250.000. Material cartográfico, 2010.

FERNANDES, F. B. P; ANDRADE, E. M; FONTENELE, S. B.; MEIRELES, A. M.; RIBEIRO, J. A. Análise de agrupamento como suporte à gestão qualitativa da água subterrânea no semiárido cearense. Revista Agro@mbiente On-line, v. 4, n. 2, p. 86-95, jul-dez, 2010.

FRAGA, C.G. Origem de fluoreto em águas subterrâneas dos sistemas aquíferos Botucatu e Serra Geral da Bacia do Paraná. 1992, 195f.. Tese (Doutorado). Instituto de Geociências, Programa de pós graduação em Recursos Mineirais e Hidrogeologia, Universidade de São Paulo (USP). São Paulo, 1992.

GASTMANS, D. Hidrogeologia e hidroquímica do Sistema Aquífero Guarani na porção ocidental da bacia sedimentar do Paraná. 2007. 238p. (Tese Doutorado). Instituto de Geociências e Ciências Exatas da Universidade Estadual Paulista. 238 p. São Paulo, 2007.

GULER, C., THYNE, G.D., MCCRAY, J.E., TURNER, A.K. Evaluation of graphical and multivariate statistical methods for classification of water chemistry data. Hydrogeology Journal, 10, 455-474, 2002 .

HAUSMAN, A. Comportamento do freático nas áreas basálticas do Rio Grande do Sul. Boletim Paranense de Geografia. $n^{\circ} 18 / 20$ p. 177-215. 1966.

LISBOA, N.A. Fácies, estratificações hidrogeoquímicas e seus controladores geológicos, em unidades hidrogeológicas do sistema aquífero Serra Geral, na bacia do Paraná, Rio Grande do Sul. 135p. 1996. Tese (doutorado). Instituto de Geociências, Programa de Pós-Graduação em Geociências. Universidade Federal do Rio Grande do Sul. Porto Alegre, 1996.

MACHADO, J. L. F; e FREITAS, M. A. Hydrochemistry of Serra Geral Aquifer In Western Santa Catarina State. 1st Joint World Congress on Groundwater. Anais...Fortaleza. 31/07 a 04/08 de 2000.

MANASSES, F. ROSA FILHO, E. F., BITTENCOURT, A. V. L. Estudo Hidrogeoquímico da For- mação Serra Geral na Região Sudoeste do Estado do Paraná. Águas Subterrâneas, v.21, n. 2, p. 49-58, 2007.

MIZUNO, Moema Guimarães Morgado. Hidroquímica das águas subterrâneas do Distrito Federal. 2012. 131 f. Dissertação (Mestrado em Geologia). Universidade de Brasília, Brasília, 2012.

MOCELIN, R. C., FERREIRA, F. J. F. Conectividade e compartimentação dos sistemas aquíferos Serra Geral e Guarani no sudoeste do estado do Paraná, Brasil. Revista Brasileira de Geociências, São Paulo, v. 39, n. 3, 2009.

MONTEIRO, A. B.; CORREIA FILHO, F. L.; FREIRE, P. K. C.; DE SOUZA, N. G.; SOARES FILHO, A. R. Análise Estatística Multivariada de Dados Hidroquímicos do Aquífero Cabeças - Sudeste da Bacia Sedimentar do Parnaíba - PI. In: Anais do XVI Congresso Brasileiro de Águas Subterrâneas e XVII Encontro Nacional de Perfuradores de Poços. São Luís, MA, 2010.

NANNI, A. et al. Fluoride characterization by principal component analysis in the hydrochemical facies of Serra Geral Aquifer System in Southern Brazil. An. Acad. Bras. Ciênc. [online]., v.80, n.4, pp. 693-701, 2008.

NANNI, A.S. ROISENBERG, A. HOLLANDA, M. H. B. M., MARIMON, M. P. C., VIERO, A. P., SCHEIBE, L. F. Fluoride in the Serra Geral Aquifer System: Source Evaluation Using Stable Isotopes and Principal Component Analysis. Journal of Geological Research, v. 2013, Article ID 309638, 9 pages, 2013.

REGINATO, P.A.R. Integração de Dados Geológicos para Prospecção de Aquíferos Fraturados em Trecho da Bacia Hidrográfica Taquari-Antas (RS). 2003, 254p.Tese (Doutorado em Engenharia). Escola de Engenharia, Programa de Pós-Graduação em Engenharia de Minas, Metalúrgica e dos Materiais. Universidade Federal do Rio Grande do Sul. Porto Alegre, 2003.

REGINATO, P. A. R.; STRIEDER, Adelir José. Caracterização Hidrogeológica e Potencialidades dos Aquíferos Fraturados da Formação Serra Geral na Região Nordeste do Estado do Rio Grande do Sul. In: XIII CONGRESSO BRASILEIRO DE ÁGUAS SUBTERRÂNEAS， 2004, Cuiabá. Anais...XIII Congresso Brasileiro de Águas Subterrâneas. SÃO PAULO: ABAS, 2004. v. 1.

REGINATO, P.A.R.; AHLERT, S.; GILIOLI, K.C.; CEMIN, G. Caracterização hidrogeológica e hidroquímica do aquífero livre do manto de alteração da Formação Serra Geral, na bacia hidrográfica Taquari-Antas, região nordeste do estado do Rio 
Relação entre padrões hidroquímicos e as profundidades de fraturas com entradas de água em rochas vulcânicas ácidas da formação serra geral

Grande do Sul. Ambi-Agua, Taubaté, v. 7, n. 1, p. xxxxx, 2012.

REGINATO, P.A.R. \& GOTTARDO, E. Mapeamento Hidrogeológico do Município de Veranópolis. Secretaria da Agricultura/Prefeitura Municipal de Veranópolis (RS). Relatório Técnico de Estágio. 30 pgs, Veranópolis, 1994.

REGINATO, P. A. R.; AHLERT S.; SCHNEIDER, V. E.; Caracterização hidroquímica do sistema aquífero Serra Geral na região nordeste do Rio Grande do Sul. Águas Subterrâneas, v. 27, n. 1, p. 65-78, 2013.

REGINATO, P. A. R.; LEÃO, M. I.; BORTOLIN, T. A.; DUTRA, T. O; ATHAYDE, G. B.; ATHAYDE, C. V. M. Circulação da água subterrânea nas rochas vulcânicas da formação serra geral na região nordeste do estado do Rio Grande do Sul. IN: $15^{\circ}$ CONGRESSO BRASILEIRO DE GEOLOGIA DE ENGENHARIA E AMBIENTAL, 2015. Bento Gonçalves. Anais... ABGE, 2015.

ROISENBERG, A.; VIERO, A.P. O Vulcanismo Mesozoico da Bacia do Paraná no Rio Grande do Sul. In: Holz, M.; De Ros, L.F. (Edit.). Geologia do Rio Grande do Sul. Porto Alegre: CIGO/UFRGS. Porto Alegre, 2000. 444p. il.- Edição Revista, 2002.
SCHLUMBERGER WATER SERVICES. Software AcquaChem 5.1. Canadá, 2008.

SCHLUMBERGER WATER SERVICES. Software Visual Poços Pro. Canadá, 1998.

STIFF, H.A. The interpretation of chemical water analysis by means of paterns. Journal of Petroleoum Technology, v. 3, n. 10, p.15-17. 1951.

SCHOELLER, H. Utilité de la notion des exchanges de bases pour la comparasion des eaux souterraines. Société Géologie Comptes Rendus Sommaire et Bulletin, v. 5, n. 5, p. 651-657. 1935.

SYSTAT. Statistical and Graphical Software. Estados Unidos, 2007.

VICINI, L.; SOUZA, A.M.,. Análise multivariada da teoria à prática. Senior design project. Universidade Federal de Santa Maria, CCNE, Manual. Santa Maria, 2005.

VIERO, Ana Cládia; SILVA, Diogo Rodrigues Andrade da (Orgs.). Geodiversidade do Estado do Rio Grande do Sul. CPRM, 2010. 1 DVD. Programa Geologia do Brasil - PGB. Levantamento da Geodiversidade. Porto Alegre, 2010. 